\title{
Energy Absorption of Pultruded Hybrid Glass/Graphite Epoxy Composites under High Strain-Rate SHPB Compression Loading
}

\author{
Seyed Soheil Daryadel*, Cameron Ray, Tejas Pandya, P. Raju Mantena \\ Composite Structures and Nano-Engineering Research, Department of Mechanical Engineering, University of \\ Mississippi, Oxford, USA \\ Email: sdaryade@go.olemiss.edu
}

Received 1 May 2015; accepted 2 June 2015; published 5 June 2015

Copyright (C) 2015 by authors and Scientific Research Publishing Inc.

This work is licensed under the Creative Commons Attribution International License (CC BY). http://creativecommons.org/licenses/by/4.0/

c) (i) Open Access

\begin{abstract}
In this study, the dynamic response and energy absorption characteristics of different combinations of fiber-reinforced pultruded hybrid composites made of unidirectional glass and graphite fiber/epoxy have been investigated. High strain-rate compression experiments were conducted on cylindrical specimens at an average strain rate of 700/s using a modified Split Hopkinson Pressure Bar (SHPB). Failure was monitored with a high-speed video camera, and effects of hybridization on the dynamic behavior of pultruded composites were evaluated. It was found that for a given fiber volume fraction, placing glass fibers in the inner core results in a higher ultimate compressive strength, specific energy absorption, and in general a better dynamic performance with lower density.
\end{abstract}

\section{Keywords}

Pultruded Composites, Hybrids, Dynamic Compressive Response, SHPB

\section{Introduction}

Fiber-reinforced pultruded composites are being used frequently in many advanced applications due to their many advantages such as structural strength, improved mechanical properties, low weight, and durability [1] [2]. These properties, along with their low-cost, enabled pultruded composites to replace traditional materials such as steel, wood, aluminum, and other composites in structural applications [3]. As a result of increased performance demands, further study is required for the optimal used of pultruded composite materials in various

*Corresponding author.

How to cite this paper: Daryadel, S.S., Ray, C., Pandya, T. and Mantena, P.R. (2015) Energy Absorption of Pultruded Hybrid Glass/Graphite Epoxy Composites under High Strain-Rate SHPB Compression Loading. Materials Sciences and Applications, 6, 511-518. http://dx.doi.org/10.4236/msa.2015.66054 
applications.

Glass and graphite are often used as fiber materials in pultruded and other composites. Glass fibers generally provide good performance at low-cost. Although they possess high tensile strength, their relatively low tensile modulus is a disadvantage in many applications. Graphite fibers, on the other hand, have a very high tensile modulus as well as high strength and low weight. Disadvantages of graphite fibers include low impact resistance and higher cost [1] [2]. Several investigations have been performed on pultruded glass and graphite/epoxy "hybrids" in the Composite Materials Research Laboratory at the University of Mississippi [2]-[9]. By the "hybridization" of both glass and graphite fibers in various proportions within the same epoxy matrix, structures can be designed to achieve optimal balance of the two materials' properties. For example, Kumar and Mantena [2] investigated the characteristics of pultruded cylindrical rods under static and dynamic torsional modes of deformation. While pure glass/epoxy exhibited higher shear modulus than pure graphite/epoxy, the hybridization of these two materials with specific amount of glass fibers in the outer shell region resulted in better dynamic performance. Low-velocity impact response characteristics and the influence of hybridization on the crashworthiness and energy-absorption of pultruded glass-graphite/epoxy composite beams were also investigated using low-velocity drop weight impact test system [8] [9]. Hybrids with graphite fibers located in the outer region showed high flexural stiffness, propagation energy, ductility, and failure index. However, they had lower initiation energy and a greater tendency to delaminate [9].

The behavior of fiber-reinforced composites under high strain-rate loading is a topic of ongoing investigations. A variety of testing methods have been employed for investigating the fiber orientation [10], specimen geometry [11] [12], and strain-rate effects [12]-[23] in different materials. For instance, some studies have found compressive strength and modulus to be dependent on strain-rate, with varying sensitivities reported, while others reported no strain-rate effects. Recently SHPB experimental technique has been used increasingly to study fiberreinforced composites. Yokoyama and Nakai [22] performed SHPB high strain-rate compression tests on cubic specimens of carbon/epoxy laminates in all three principal material directions and discussed the failure mechanism of the composites. They reported an increase of the modulus and ultimate strength, and decrease of energy absorbed up to failure strain with increasing strain-rate when compression is along the fiber direction. Also Koerber and Camanho [23] compared the longitudinal SHPB compression response at an average strain-rate of about 100/s of unidirectional carbon-epoxy samples with quasi-static test result. While an increase was observed for the longitudinal compressive strength, it was found that the longitudinal compressive modulus is not strainrate sensitive.

The improved characteristics of fiber-reinforced pultruded composites, as well as their high specific energy absorption due to their failure mechanisms, make them a good candidate for use in structures that are likely to experience extreme dynamic loading, e.g., aircrafts, ships, and armored vehicles [24] [25]. In the design of these structures, the ability of materials to absorb and dissipate energy effectively during impact events is one of the most important criteria. Therefore, a thorough understanding of the dynamic behavior and energy absorption characteristics of fiber-reinforced pultruded composites is necessary.

The purpose of this work is to study the energy absorption and dynamic behavior of glass, graphite, and hybrid glass-graphite fiber/epoxy pultruded composites, compressed axially along the fiber direction at high strainrate. The dynamic compression tests were conducted using a modified SHPB test system. A high-speed camera was also utilized to record and study the crack propagation and failure mechanism during the SHPB compression tests.

\section{Specimen Fabrication}

Pultrusion is a manufacturing process for producing structures of constant cross-section (e.g., I-beams, tubes, and rods) in which continuous fibers (unidirectional or woven) are pulled through a resin bath, and the resulting fiber/resin mixture is then pulled through a series of preform plates and a heated die, which forms the product into its final shape. It is a relatively fast way to produce strong and lightweight structural components [2].

Cylindrical rods of $9.6 \mathrm{~mm}$ diameter containing glass, graphite and hybrid combinations of the two fiber types in an epoxy matrix were produced [6] using a single pass of the pultrusion process. The hybrid rods were manufactured to be symmetric about the neutral axis to avoid the effects of temperature changes during production, which would lead to warping or bending in the final product. Both preform and post-die plates were employed to keep the fibers in the intended placement. The cylindrical rods had a total fiber volume fraction of $60 \%$ ( $40 \%$ 
epoxy). Each hybrid rod is defined by the fiber volume fraction of each fiber type, and by the location of each fiber type relative to the neutral axis. For example, GR30, a 30\% graphite core/30\% glass shell specimen has 30\% graphite fiber volume fraction and $30 \%$ glass fiber volume fraction, with the graphite fibers in the inner core region and the glass fibers in the outer shell region. The glass fibers used were E-glass (PPG 2001 \# 112), the graphite fibers were AS4W-12K (Fiberite), and the resin was Shell EPON-826/W. Cylindrical specimens were cut precisely with $7.2 \mathrm{~mm}( \pm 0.1 \mathrm{~mm})$ length for SHPB compression tests. Figure 1 shows the cross-sections of the pultruded hybrid combinations, along with the corresponding percent fiber volume and specimen ID code. The average bulk densities of the pultruded hybrid specimens are shown in Table 1 . As expected graphite fiber hybrids are lighter and have lower density.

\section{Apparatus}

SHPB, or Kolsky bar, developed first by Kolsky in 1949 [26], is a well-known technique for characterizing materials at high strain-rates. All tests reported in this article were carried out on the modified SHPB in the Blast and Impact Dynamic Lab at the University of Mississippi, MS. Maraging steel bars of $19.02 \mathrm{~mm}$ diameter were used as striker, incident and transmission bars. In order to avoid friction and shear effects on the specimens during compression tests, petroleum jelly was applied for mounting the specimen in between incident and transmission bar-ends.

A HyperVision HPV-2 High-Speed Video Camera (Shimadzu Scientific Instrument) was used to monitor the deformation/failure process during SHPB compression loading. Due to high recording speed of camera and need for high-intensity lighting, two $1000 \mathrm{~W}$ strobes (Photogenic Power Lights, PL2500DR) were employed to provide necessary light for recording. A sound trigger system was used for triggering the camera and strobes by the impact sound of striker and incident bars. 102 frames were captured for each experiment at a frame rate of 500,000 fps.

\section{Results and Discussion}

SHPB high strain-rate compression tests were performed on pure glass, pure graphite, and the hybrids of glassgraphite fiber/epoxy specimens (shown in Figure 1) to study their dynamic behavior and energy absorption characteristics. Figure 2 shows the typical stress wave pulses (incident, reflected and transmitted) recorded from strain gages on the incident and transmission bars. The required dynamic equilibrium condition has been validated

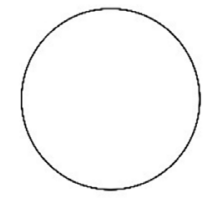

$60 \%$ Glass/Epoxy

[GL60]

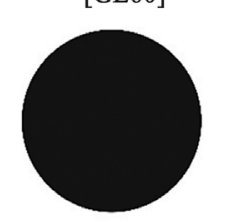

$60 \%$ Graphite/Epoxy

[GR60]

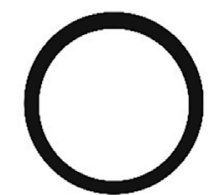

$48 \%$ Glass Core 12\% Graphite Shell [GL48]

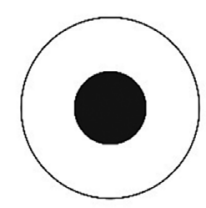

$12 \%$ Graphite Core 48\% Glass Shell [GR48]

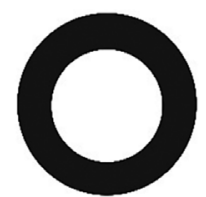

$30 \%$ Glass Core 30\% Graphite Shell [GL30]

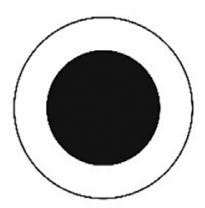

$30 \%$ Graphite Core $30 \%$ Glass Shell [GR30]

Figure 1. Cross-sections of the pultruded hybrid combinations.

Table 1. Measured average bulk densities of the pultruded hybrid specimens.

\begin{tabular}{ccccc}
\hline & GL60 & GL48 \& GR12 & GL30 \& GR30 & GR60 \\
\hline Density $\left(\mathrm{kg} \cdot \mathrm{m}^{-3}\right)$ & 2084 & 1953 & 1808 & 1603 \\
\hline
\end{tabular}


in all tests by estimating the stresses developed at opposite faces of each specimen under compression (Figure 3). It should be noted that all data are reported up to the shattering point of each specimen as captured by the highspeed camera.

Figure 4 shows a typical stress-strain curve for all the hybrid combinations at strain-rate of $\sim 700 / \mathrm{s}$. An average of 5 specimens were tested for each fiber combination. With a change in fiber type and fiber location in the specimens, the stiffness changes accordingly. Pure graphite/epoxy specimens (GR60) show the highest stiffness, and stiffness decreases with increasing glass fiber content. Also locating the graphite fibers in the core region results in higher stiffness. The average ultimate compressive strength is summarized in Figure 5. Pure glass/ epoxy (GL60) has higher compressive strength than pure graphite/epoxy (GR60). Results indicate a difference of more than $200 \mathrm{MPa}$ in compressive strength between these two composites. Hybrids with glass fibers located in the inner core exhibit higher compressive strength compared to those with glass fibers in the outer shell. The hybrids having $48 \%$ glass fibers in the inner core and 12\% graphite fibers in the outer shell (GL48) demonstrate marginally higher compressive strength than pure glass/epoxy. The specific energy absorption (energy absorbed per unit mass) under SHPB compression loading is compared in Figure 6. Among all the combinations, $60 \%$ glass/epoxy (GL60) and the hybrid with 48\% glass fibers in the core region (GL48) show the highest specific energy absorption, while hybrids with $30 \%$ graphite in core (GR30) absorbed the least amount of energy.

Failure initiation and propagation in the specimens were monitored with the high-speed video camera at a frame rate of 500,000 fps. Figure 7 shows typical high-speed images and the associated stress-time history obtained for a GL60 specimen at various stages during SHPB compression test at a strain-rate of about 700/sec. The whole event for this sample takes about $60 \mu$ s. As can be seen in Figure 7, the sample appears to be undergoing uniform compression up to the peak load at about $50 \mu$ s. The surface crack and shattering initiated at about

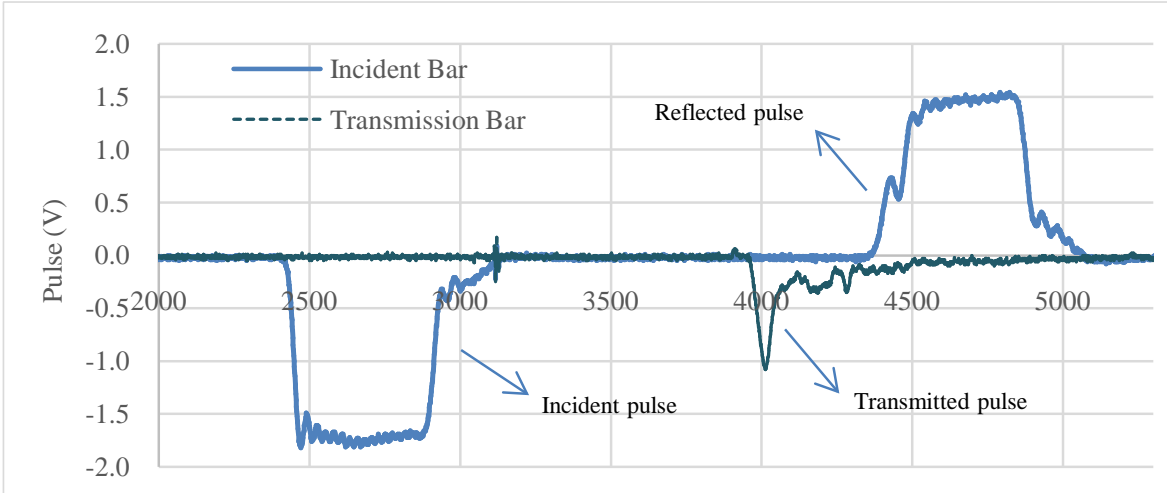

Figure 2. Typical incident, reflected and transmitted pulses in SHPB compression test on a pultruded composites specimen.

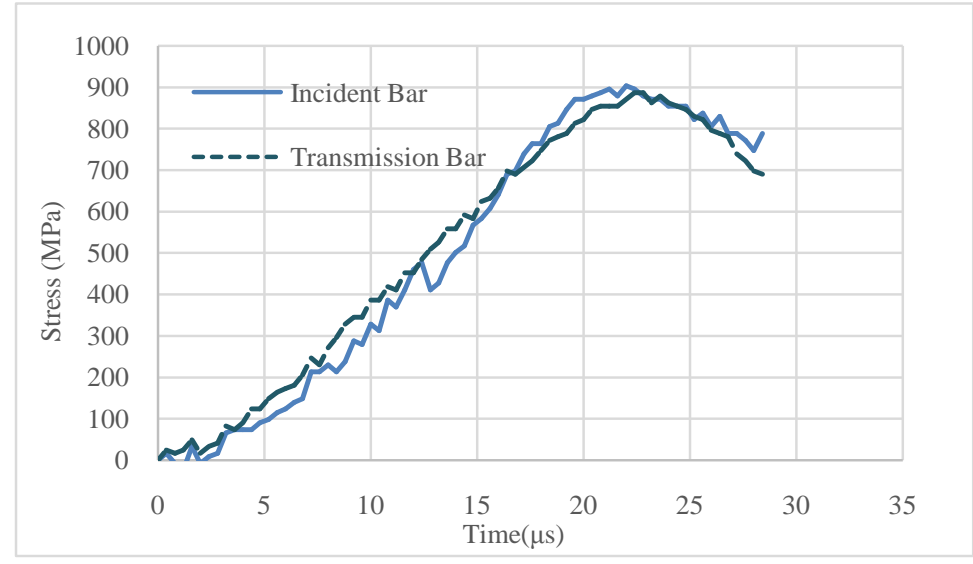

Figure 3. Validation of the equilibrium stress state obtained in SHPB compression test. 


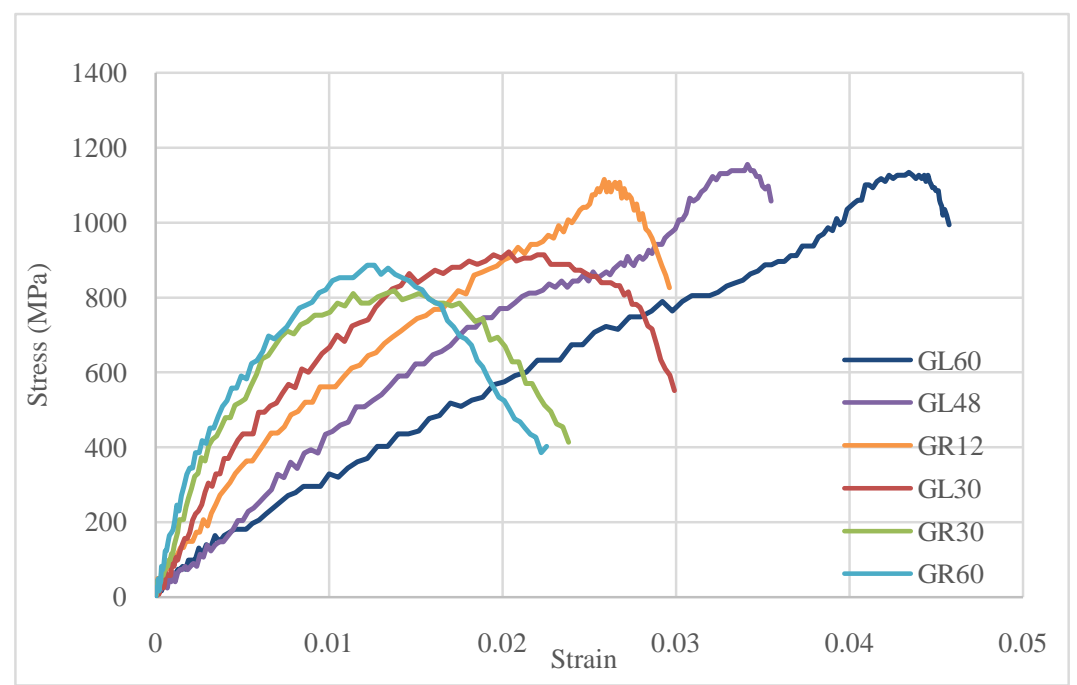

Figure 4. Stress-strain SHPB compression response for different combinations of the pultruded hybrids at strain-rate of $\sim 700 / s$.

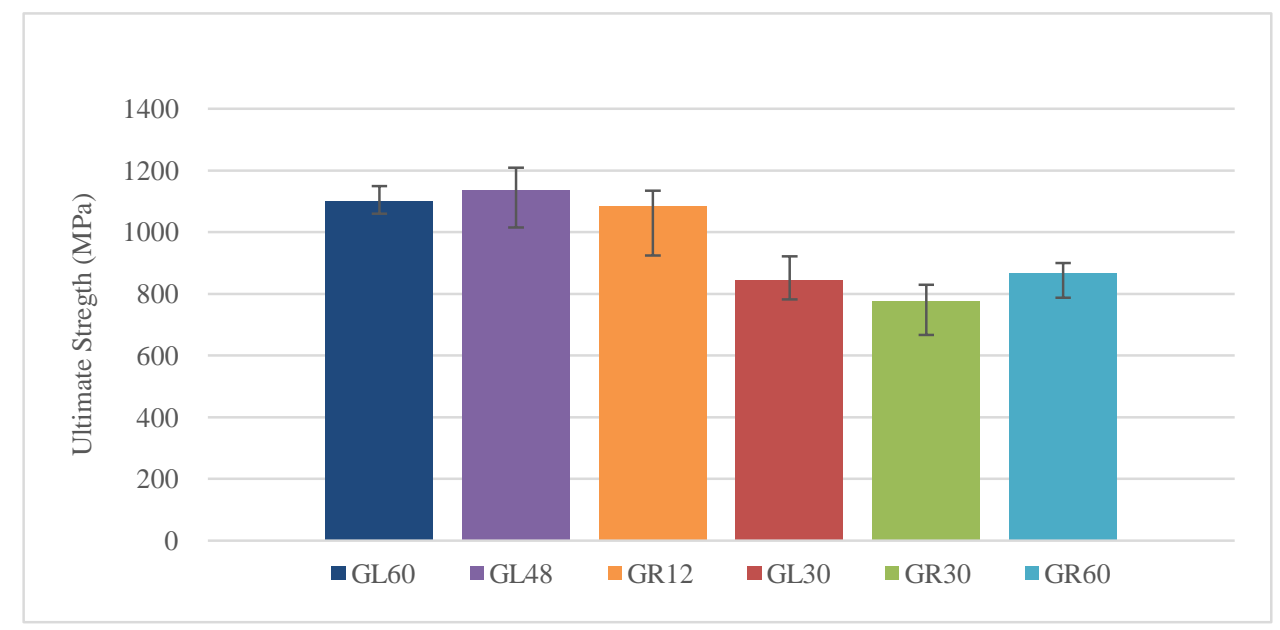

Figure 5. Average ultimate compressive strength for different combinations of the pultruded hybrids at strain-rate of $\sim 700 / \mathrm{s}$.

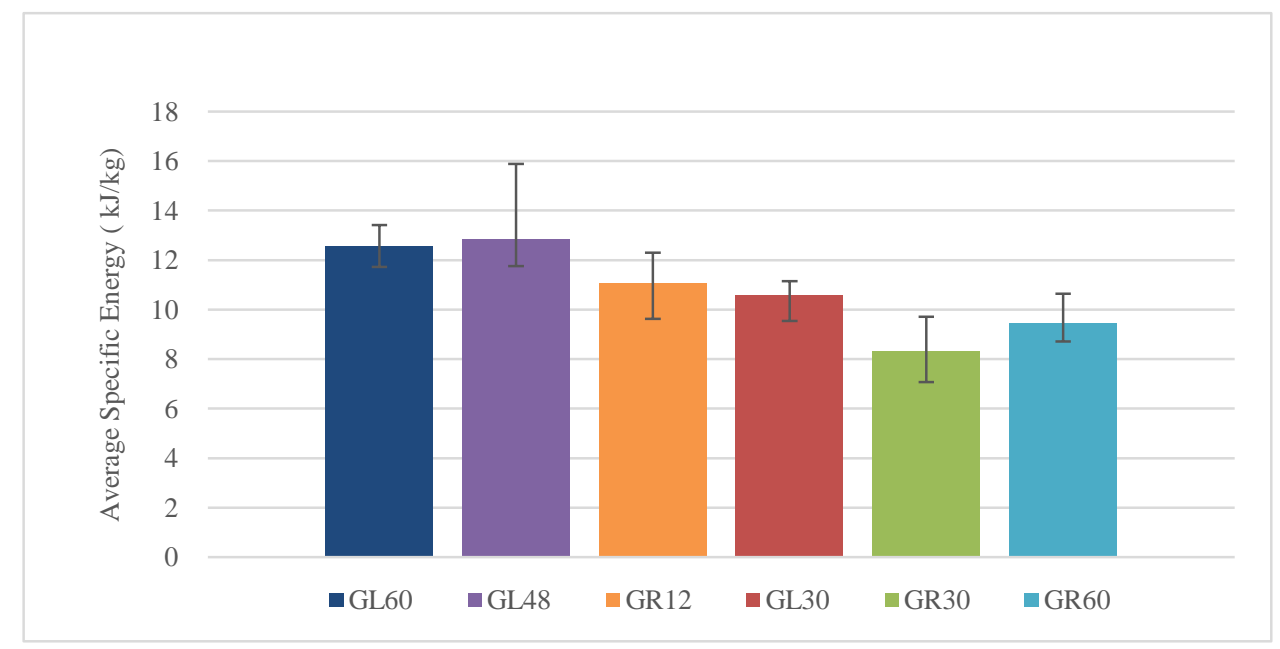

Figure 6. Average specific energy absorption for different combinations of the pultruded hybrids at strain-rate of 700/s. 

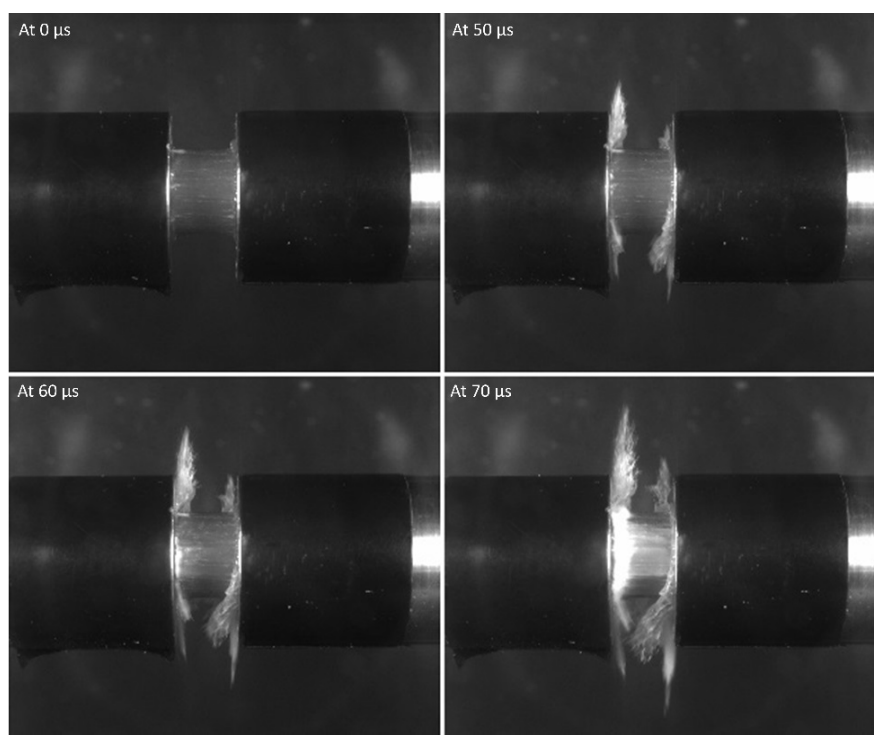

(a)

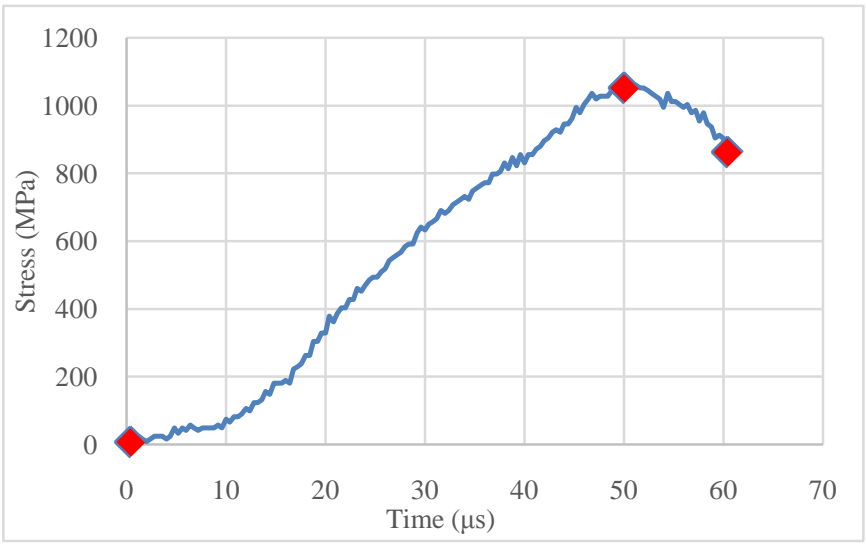

(b)

Figure 7. (a) High-speed images; (b) Associated stress-time history showing the failure process of a GL60 specimen at strain-rate of $~ 700 / s$.

$60 \mu$ s. The image at $70 \mu$ s shows an extensively damaged/shattered stage of the specimen. The results illustrate that the entire specimen has not been extensively damaged at the peak stress. It appears that compression failure is dominated by plastic deformation of the matrix at peak load followed by debonding of the fiber-matrix and fiber-fiber interfaces. High-speed digital images of the other samples showed similar behavior.

\section{Conclusion}

In this study, pultruded hybrid composite specimens made of glass and graphite/epoxy with different combinations of fibers were dynamically loaded using a modified compression SHPB. Glass fiber/epoxy specimens exhibited higher ultimate compressive strength and specific energy absorption compared to pure graphite/epoxy samples, while graphite hybrid showed higher stiffness. It was observed that the hybrids' compressive stiffness, ultimate strength and specific energy absorption are highly dependent on the type and location of fibers. Increasing graphite fiber volume fraction and placing the graphite fibers in the core region provided higher stiffness (steeper slope in the stress-strain curves) compared to the other combinations. It was also found that hybridization of these two materials, $48 \%$ glass fibers in the inner core and $12 \%$ graphite fibers in the outer shell, results in a pultruded composite structure with higher ultimate strength and specific energy absorption, compared to the pure glass/epoxy and pure graphite/epoxy pultruded products. In addition, a high-speed camera used for 
studying the crack propagation and failure mechanism, showed that the specimens were not visibly damaged at the peak load, and the surface starts to shatter few microseconds after the peak load.

\section{Acknowledgements}

Authors wish to acknowledge funding received from US Army Research Office-DURIP Grant \# W911NF-13-10248 for the high-speed digital cameras used in this research. The authors would also like to thank Mr. P. Matthew Lowe, Mr. Kiyun Kim, Mr. Mohammad Afrough, and Mr. Damian Stoddard for their technical help in material preparation and performing the SHPB tests.

\section{References}

[1] Gibson, R.F. (2007) Principles of Composite Material Mechanics. 2nd Edition, CRC Press, Boca Raton.

[2] Kumar, S.S. and Mantena, P.R. (1996) Dynamic and Static Torsional Characterization of Pultruded HybridCylindrical Composite Rods. Journal of Composite Materials, 30, 918-932. http://dx.doi.org/10.1177/002199839603000804

[3] Vaughan, J.G., Roux, J.A., and Mantena, P.R. (1992) Characterization of Mechanical and Thermal Properties of Advanced Composite Pultrusions. Proceedings of the 1992 NSF Design and Manufacturing Systems Conference, Atlanta, 8-10 January 1992, 1141-1145.

[4] Mantena, P.R., Vaughan, J.G., Donti, R.P. and Kowsika, M.V. (1992) Influence of Process Variables on the Dynamic Characteristics of Pultruded Graphite-Epoxy Composites. Vibro-Acoustic Characterization of Materials and Structures, ASME, 14, 147-154.

[5] Mantena, P.R., Vangipuram, R. and Vaughan, J.G. (1994) Dynamic Flexural Properties of Pultruded Glass/Graphite Hybrid Composites. 39th International SAMPE Symposium, Anaheim, 11-14 April 1994, 174-182.

[6] Nori, C.V., Mantena, P.R. and McCarty, T.A. (1996) Experimental and Finite Element Analysis of Pultruded GlassGraphite/Epoxy Hybrids in Axial and Flexural Modes of Vibration. Journal of Composite Materials, 30, 1996-2018. http://dx.doi.org/10.1177/002199839603001803

[7] Ranganathan, S. and Mantena, P.R. (2003) Axial Loading and Buckling Response Characteristics of Pultruded Hybrid Glass-Graphite/Epoxy Composite Beams. Journal of Reinforced Plastics and Composites, 22, 7671-7679. http://dx.doi.org/10.1177/073168403024566

[8] Kowsika, M.V. and Mantena, P.R. (1999) Static and Low-Velocity Impact Response Characteristics of Pultruded Hybrid Glass-Graphite/Epoxy Composite Beams. Journal of Thermoplastic Composite Materials, 12, 121-132. http://dx.doi.org/10.1177/089270579901200203

[9] Kowsika, M.V., Mantena, P.R. and Balasubramaniam. (2002) Energy Absorption and Dissipation Characteristics of Pultruded Glass-Graphite/Epoxy Hybrid Composite Beams. Journal of Thermoplastic Composite Materials, 15, 227252. http://dx.doi.org/10.1177/0892705702015003453

[10] Vinson, J.R. and Woldesenbet, E. (2002) Fiber Orientation Effects on High Strain Rate Properties of Graphite/Epoxy Composite. Journal of Composite Materials, 35, 509-521. http://dx.doi.org/10.1177/002199801772662136

[11] Woldesenbet, E. and Vinson, J.R. (1999) Specimen Geometry Effects on High-Strain-Rate Testing of Graphite/Epoxy Composites. AIAA Journal, 37, 1102-1106. http://dx.doi.org/10.2514/2.820

[12] Harding, J. (1993) Effect of Strain Rate and Specimen Geometry on the Compressive Strength of Woven GlassReinforced Epoxy Laminates. Composites, 24, 323-332. http://dx.doi.org/10.1016/0010-4361(93)90042-7

[13] Asprone, D., Cadoni, E., Prota, A. and Manfredi, G. (2009) Strain-Rate Sensitivity of a Pultruded E-Glass/Polyester Composite. Journal of Composites for Construction, 13, 558-564. http://dx.doi.org/10.1061/(ASCE)CC.1943-5614.0000036

[14] Hosur, M.V., Alexander, J., Vaidya, U.K. and Jeelani, S. (2001) High Strain Rate Compression Response of Carbon/ Epoxy Laminate Composites. Composite Structures, 52, 405-417. http://dx.doi.org/10.1016/S0263-8223(01)00031-9

[15] Hsiao, H. M., and Daniel, I. M. (1998) Strain Rate Behavior of Composite Materials. Composites Part B: Engineering, 29, 521-533. http://dx.doi.org/10.1016/S1359-8368(98)00008-0

[16] Hsiao, H.M., Daniel, I.M. and Cordes, R.D. (1998) Dynamic Compressive Behaviour of Thick Composite Materials. Experimental Mechanics, 38, 172-180. http://dx.doi.org/10.1007/BF02325740

[17] Huang, Z., Nie, X. and Xia, Y. (2004) Effect of Strain Rate and Temperature on the Dynamic Tensile Properties of GFRP. Journal of Materials Science, 39, 3479-3482. http://dx.doi.org/10.1023/B:JMSC.0000026956.45427.68

[18] Sierakowski, R.L. (1997) Strain Rate Effects in Composites. Applied Mechanics Review, 50, 741-761. http://dx.doi.org/10.1115/1.3101860 
[19] El-Habak, A.M.A. (1993) Compressive Resistance of Unidirectional GFRP under High Rate of Loading. Journal of Composites, Technology and Research, 15, 311-317. http://dx.doi.org/10.1520/CTR10384J

[20] Okoli, I. (2001) The Effect of Strain Rate and Failure Modes on the Failure Energy of Fiber Reinforced Composites. Composite Structures, 54, 299-303. http://dx.doi.org/10.1016/S0263-8223(01)00101-5

[21] Tay, T.E., Ang, H.G. and Shim, V.P.W. (1995) An Empirical Strain Rate-Dependent Constitutive Relationship for GlassFibre Reinforced Epoxy and Pure Epoxy. Composite Structures, 33, 201-210. http://dx.doi.org/10.1016/0263-8223(95)00116-6

[22] Yokoyama, T., Nakai, K. and Odamura, T. (2007) High Strain-Rate Compressive Characteristics of a Unidirectional Carbon/Epoxy Composite: Effect of Loading Directions. In: Gdoutos, E.E., Ed., Experimental Analysis of Nano and Engineering Materials and Structures, Springer Netherlands, 681-682.

[23] H. Koerber, Camanho, P.P. (2011) High Strain Rate Characterization of Unidirectional Carbon-Epoxy IM7-8552 in Longitudinal Compression. Composites Part A: Applied Science and Manufacturing, 42, 462-470. http://dx.doi.org/10.1016/j.compositesa.2011.01.002

[24] Alghamdi, A.A.A. (2001) Collapsible Impact Energy Absorbers: An Overview. Thin-Walled Structures, 39, $189-213$. http://dx.doi.org/10.1016/S0263-8231(00)00048-3

[25] Lu, G. and Yu, T. (2003) Energy Absorption of Structures and Materials. Woodhead Publishing Limited, Sawston, 144-173.

[26] Kolsky, H. (1949) An Investigation of the Mechanical Properties of Materials at Very High Rates of Loading. Proceedings of the Physical Society. Section B, 62, 676-700. http://dx.doi.org/10.1088/0370-1301/62/11/302 